\title{
Análise Físico-Química das Águas de Três Poços Amazonas no Centro da Cidade de Pambal-PB
}

\section{Physical-Chemical Analysis of the Water From Three Amazonas in the City Center of Pombal-PB}

\author{
Diêgo Lima Crispim * \\ Luiz Fernando de Oliveira Coelho **** Andréa Maria Brandão Mendes de Oliveira ** \\ Sanduel Oliveira de Andrade ***** Alan Dél Carlos Gomes Chaves ***
}

\section{Resumo:}

A água subterrânea é uma fonte imprescindível para o abastecimento público de diversas cidades da região semiárida, haja vista que vários municípios passam por períodos prolongados de estiagem e secas severas, fazendo com que os reservatórios utilizados para o abastecimento de água tenham redução drástica dos seus níveis de água, e consequentemente, prejudicando o abastecimento. $\mathrm{Na}$ cidade de Pombal a água proveniente do manancial subterrâneo vem sendo utilizada para suprir as necessidades e atividades diárias de alguns habitantes. Ante o exposto, o presente trabalho teve como objetivo analisar a qualidade da água de três poços tipo amazonas localizados no centro da cidade de Pombal-PB, por meio da avaliação de parâmetros físico-químicos. No período de agosto a dezembro de 2012, foram realizadas sete campanhas, e os parâmetros físico-químicos analisados foram: Cor, Turbidez, Condutividade elétrica, Sólidos totais dissolvidos, $\mathrm{pH}$, Oxigênio dissolvido (OD), Alcalinidade, Dureza total, Cloretos, Temperatura do ar e Temperatura da água. As análises foram realizadas no Laboratório de Análises de Água - LAAg, da Universidade Federal de Campina Grande, Campus de Pombal-PB. O procedimento de coleta, acondicionamento e preservação seguiram as normas estabelecidas no manual prático da Funasa. Os resultados obtidos indicaram que as amostras encontram-se dentro dos valores máximos estabelecidos pela Portaria no ${ }^{\circ} .2 .914 / 2011$ do Ministério da Saúde. Embora o parâmetro alcalinidade total não seja previsto na legislação brasileira, os valores encontrados excedem o limite máximo da OMS.

\begin{abstract}
:
Groundwater is an indispensable source for the public supply of several cities in the semi-arid region. Since several municipalities when they go through prolonged periods of droughts severe, making with what the reservoirs used for the water supply drastically reduce their water levels, and consequently impairing the supply. In the city of Pombal the groundwater spring has been used to supply the needs and daily activities of some inhabitants. The present study had the objective of analyzing water quality of three type Amazonas wells located in the center of the city of Pombal-PB, through the evaluation of physical-chemical parameters. In the period from August to December 2012, seven campaigns were carried out, which were submitted to physical-chemical analysis (Color, Turbidity, Electrical Conductivity, Total Dissolved Solids, pH, Dissolved Oxygen (DO), Alkalinity, Total Hardness, Chlorides, Air Temperature and Water Temperature). The analyzes were carried out in the at the Laboratory of Water Analysis - LAAg, Federal University of Campina Grande, Campus of Pombal-PB. The procedure of collection, conditioning and preservation followed the norms established in the practical manual of Funasa. The results obtained in the physical-chemical analyzes indicated that the samples are within the maximum values established by Ordinance no. 2.914 / 2011 of the Ministry of Health. Although the total alkalinity parameter does not have a limit set by the ordinance and resolution used in this study, it has been found that the results of the samples are unacceptable for human consumption based on WHO reference.
\end{abstract}

* Doutorando em Engenharia Civil pela UFPA

** Prof $^{a} \operatorname{Dr}^{a}$ da UFCG na Unidade Acadêmica de Ciências e Tecnologia Ambiental (UACTA/CCTA)

*** Doutorando de Engenharia Agricola pela UFRB

**** Graduado em Gestão Ambiental pelo Centro Universitário Estácio Uniseb

***** MSc. em Sistemas Agroindustriais pela UFCG . Professor no Curso Técnico em Agroecologia, no município de Pombal-PB
Palavras-chave:

Água subterrânea, Qualidade da água, Potabilidade.

Key-Words:

Groundwater, Water quality, Potability. 


\section{INTRODUÇÃO}

A escassez de água potável é uma realidade no semiárido nordestino, resultante das condições climatológicas, da utilização predatória, de um gerenciamento inadequado e da intensificação de atividades de caráter poluidor que afetam diretamente os recursos hídricos (CRISPIM, 2013). Desta forma, tem aumentado a frequência de problemas relacionados à falta desse recurso, em condições adequadas de quantidade e qualidade para atender as necessidades básicas da população.

Observa-se atualmente, um aumento significativo na utilização das águas subterrâneas, para diversos fins, tais como o abastecimento humano, irrigação, indústria, lazer, etc. Essas águas, geralmente apresentam qualidade satisfatória e são menos susceptíveis a contaminação por elementos biológicos e químicos quando comparada as águas superficiais (ECKHARDT, 2008; MONTENEGRO; MONTENEGRO, 2012).

$\mathrm{Na}$ região semiárida, a água subterrânea é uma fonte imprescindível para o abastecimento público, haja vista que vários municípios, enfrentam prolongados períodos de estiagem e secas severas, fazendo com que os reservatórios utilizados para o abastecimento de água tenham redução drástica dos seus níveis de água, e consequentemente, prejudicando o abastecimento.

Segundo Linhares (2012), as águas subterrâneas são atualmente a principal fonte de abastecimento de água para o consumo humano em algumas cidades, como exemplo, Recife-PE, Mossoró-RN, Maceió-AL, Barreira-BA, e outros. No Brasil, aproximadamente $61 \%$ da população é abastecida com águas subterrâneas para fins domésticos, sendo $6 \%$ por poços rasos, $12 \%$ por fontes e $43 \%$ por poços profundos. Em torno de 15,6\% dos domicílios utilizam exclusivamente água subterrânea (ANA, 2005). Embora o uso do manancial subterrâneo seja complementar ao superficial em muitas regiões, em outras, representa a principal fonte hídrica (ANA, 2005).

Nos ambientes urbanos, as águas subterrâneas estão sujeitas aos vários tipos de poluição. Os aquíferos freáticos são afetados por fatores como atividades industriais, efluentes sanitários, postos de gasolina, oficinas mecânicas, presença de cemitérios, hospitais, galerias de drenagem pluvial, águas de infiltração e disposição inadequada de resíduos sólidos, que prejudicam a qualidade da água, tornando-as impróprias para consumo humano (ALMEIDA, 2007). Dessa forma, o monitoramento de parâmetros de qualidade da água caracteriza-se como um instrumento básico para avaliar alterações ambientais resultantes das atividades antrópicas (MOLOZZI et al., 2006).

Nesse sentido, o presente trabalho objetivou avaliar a qualidade água de três poços tipo amazonas localizados no centro da cidade de Pombal-PB, por meio de parâmetros físico-químicos.

\section{MATERIAL E MÉTODOS}

\subsection{Localização e caracterização da área estudada}

O município de Pombal situa-se na região oeste do estado da Paraíba, Mesorregião do Sertão Paraibano e Microrregião de Sousa, distando aproximadamente $371 \mathrm{~km}$ da capital João Pessoa (Figura 1). A cidade encontra-se a aproximadamente $184 \mathrm{~m}$ de altitude, e possui área total de $889 \mathrm{~km}^{2}$ (IBGE, 2010).

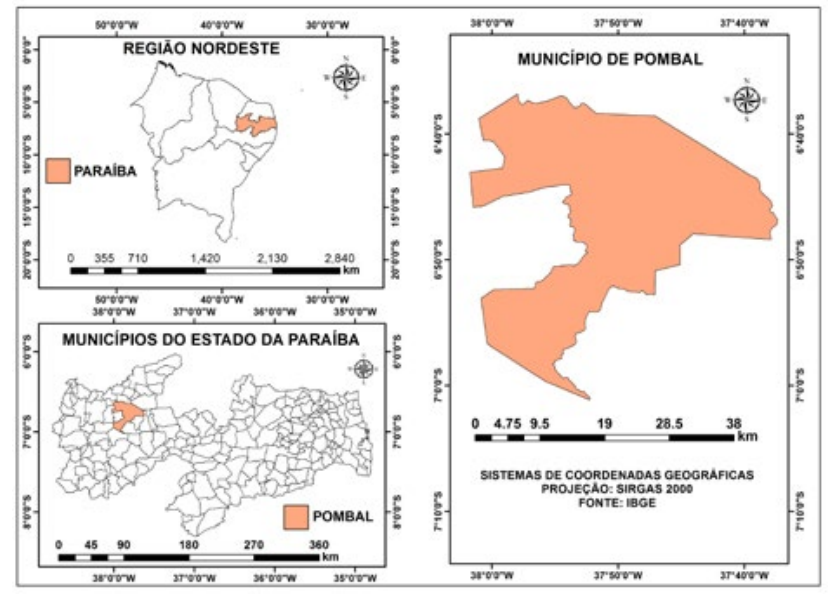

Figura 1: Localização do município de Pombal - PB. Fonte: Autores (2017).

Limita-se ao Norte com os municípios de Santa Cruz, Lagoa e Paulista, ao Leste, com Condado, ao Sul, com São Domingos, São Bentinho, Cajazeirinhas, Coremas e São José da Lagoa Tapada e a Oeste, com Aparecida e São Francisco. A população estimada para o ano de 2010 foi de aproximadamente 32.110 habitantes (IBGE, 2010).

O município de Pombal-PB está inserido na unidade geoambiental da Depressão Sertaneja, que representa a paisagem típica do semiárido nordestino. A vegetação é basicamente composta por Caatinga Hiperxerófila com trechos de Floresta Caducifólia.

O clima da região é do tipo BSh, segundo a classificação de Köppen, isto é, semiárido quente e seco, com precipitação pluviométrica média anual de $750 \mathrm{~mm}$, e evaporação média anual de $2000 \mathrm{~mm}$ (BRITO et al., 2013) e temperatura 
média de $28^{\circ} \mathrm{C}$.

Os tipos de solos predominantes são Luvissolos em associação com Neossolos Litólicos. $\mathrm{Na}$ área de estudo predomina o embasamento cristalino, com solos poucos profundos e com baixa capacidade de infiltração e armazenamento (MONTENEGRO; MONTENEGRO, 2012; SANTOS et al., 2013).

\subsection{Definição dos pontos de amostragem}

O estudo foi desenvolvido no centro da cidade de Pombal-PB, conforme mostra a (Figura 2).

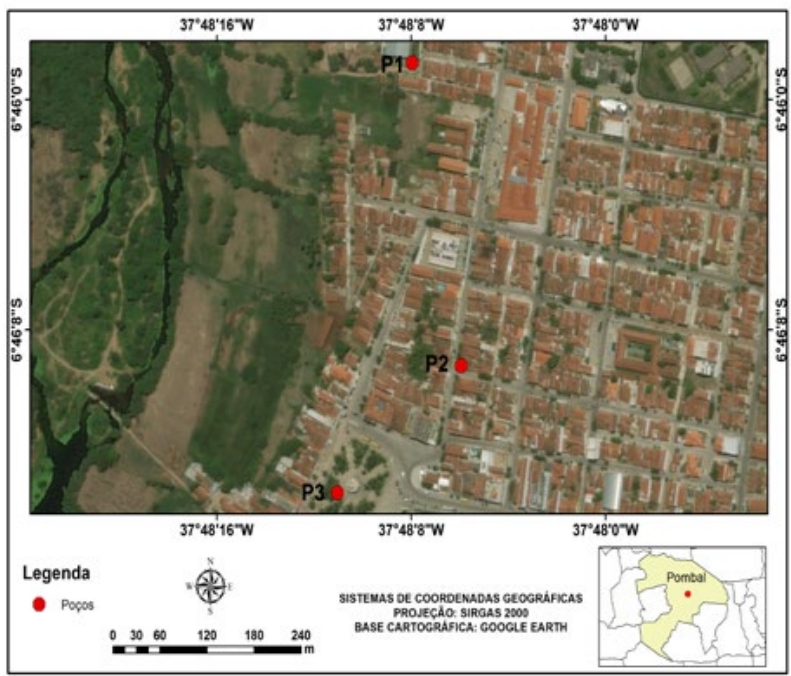

Figura 2: Localização da área de estudo.

Fonte: Autores (2017).

A avaliação da qualidade da água foi realizada em três poços tipo amazonas, cuja localização foi descrita na Tabela 1. Esse tipo de poço geralmente é escavado manualmente, mas também pode ser escavado por máquinas retroescavadeiras. São poços revestidos de alvenaria ou com peças pré-moldadas e têm a forma cilíndrica e diâmetro da ordem de um a quatro metros por cinco a vinte metros de profundidade, ou profundidade média, a depender da altura do lençol freático (GUIMARÃES, 2007).

Optou-se por esses três poços em razão de estarem em funcionamento e serem acessíveis. O P1 abastece uma lavandaria, o P2 residências e o $\mathrm{P} 3$ abastece um prédio comercial e barracas de ruas em período festivo.

A falta de informação da existência de outros poços que poderiam estar em funcionamento na área de estudo limitou à ampliação da pesquisa.

\subsection{Coleta e acondicionamento das amostras}

Foram realizadas sete campanhas de campo para coleta de água entre os meses de agosto a dezembro de 2012, sendo esse período de estiagem na região. Embora a qualidade da água sofra efeitos da sazonalidade, o período de amostragem teve como finalidade fazer uma avaliação preliminar. Todos os procedimentos de preparo dos recipientes, coleta, acondicionamento das amostras e transporte seguiram as recomendações do Manual Prático de Análise de Água (FUNASA, 2006).

\begin{tabular}{|c|c|c|c|c|}
\hline \multirow[t]{2}{*}{ Pontos } & \multirow[t]{2}{*}{ Locallzação } & \multirow[t]{2}{*}{ Atlividade } & \multicolumn{2}{|c|}{ Coordenadas Geográflicas } \\
\hline & & & Latitude & Longitude \\
\hline Poço 1 & $\begin{array}{l}\text { Lavanderia } \\
\text { Pública }\end{array}$ & $\begin{array}{l}\text { Lavagem de roupa; } \\
\text { Hligienizaçdo corporal. }\end{array}$ & $6^{\circ} 45^{\prime} 58.73^{\prime \prime} \mathrm{S}$ & $37^{\circ} 48^{\prime} 7.95^{\prime \prime} 0$ \\
\hline Poço 2 & Residência & $\begin{array}{l}\text { Limpeza de casa e } \\
\text { utensilios de cozinha; } \\
\text { Higienização corporal; } \\
\text { Lavagem de roupa; } \\
\text { Preparo de alimentos. }\end{array}$ & $6^{\circ} 469.24^{\circ} \mathrm{S}$ & $37^{\circ} 48^{\prime} 5.91^{\prime \prime} 0$ \\
\hline Poço 3 & $\begin{array}{l}\text { Praça do } \\
\text { Centenário }\end{array}$ & $\begin{array}{l}\text { Limpeza do prédio; } \\
\text { Rega de jardim; } \\
\text { Serviços sanitários. }\end{array}$ & $6^{\circ} 46^{1} 13.61^{\prime S} \mathrm{~S}$ & $37^{\circ} 18^{\prime} 11.01^{\prime \prime} \mathrm{O}$ \\
\hline
\end{tabular}

Fonte: Dados da pesquisa.

\subsection{Análises laboratoriais}

Nas amostras de água coletadas nos três pontos de amostragem, foram determinados os seguintes parâmetros: cor, turbidez, condutividade elétrica (CE), sólidos totais dissolvidos (STD), pH, oxigênio dissolvido (OD), alcalinidade, dureza total, cloretos, temperatura do ar e temperatura da água.

Em campo foram medidos o OD, temperatura do ar e da água por meio do medidor portátil (Hanna HL 9869). Os demais parâmetros foram determinados no Laboratório de Análises de Água - LAAg, da Universidade Federal de Campina Grande (UFCG-Pombal).

Os parâmetros químicos dureza total, alcalinidade e cloretos foram determinados por meio de análises titulométricas seguindo os procedimentos do Manual Prático de Análise de Água (FUNASA, 2006). As metodologias utilizadas para as análises dos parâmetros físico-químicos estão descritas na Tabela 2.

Tabela 2: Parâmetros físico-químicos avaliados e método adotado

\begin{tabular}{|c|c|}
\hline Parâmetros & Método \\
\hline Temperatura da água & Leitura direta utilizando o medidor portátil (Hanna HL 9869) \\
\hline Temperatura do ar & Leitura direta utilizando o medidor portátil (Hanna HL 9869) \\
\hline $\mathrm{pH}$ & $\begin{array}{l}\text { Método potenciométrico, utilizando-se do medidor de pH, modelo mPA- } \\
210 \text {, com leitura direta. }\end{array}$ \\
\hline Condutividade elétrica & Medicăo direta pelo Condutivimetro TEC, modelo 4 MP. \\
\hline Cor aparente & Medicão direta pelo Colorímetro, modelo Lovibond MD 200 \\
\hline Sólidos totais dissolvidos & Por meio do Condutivimetro TEC, modelo 4 MP. \\
\hline Turbidez & Medicăo direta no turbidimetro, modelo TB - 1000. \\
\hline Cloretos & Thulometria de precipitaçăo pelo Método de Mhor. \\
\hline Alcalinidade & Titulometria de neutralizaçăo. \\
\hline Dureza total & Iftulometria de complexaçāo. \\
\hline Oxigênio dissolvido & Leitura direta utilizando o medidor portátili (Hanna HL 9869) \\
\hline
\end{tabular}

Fonte: Autores (2014). 
Para a interpretação dos resultados foram considerados os limites expostos da seguinte norma: Portaria 2.914/11 do Ministério da Saúde (M.S.) que define a potabilidade da água (BRASIL, 2011); Resolução CONAMA n ${ }^{\circ}$ 396, de 03 de abril de 2008, conforme ilustra a Tabela 3.

Tabela 3: Padrões de Potabilidade nacionais

\begin{tabular}{|c|c|c|c|}
\hline Parâmetros & Unid. & $\begin{array}{c}2.914 / 11 \\
\text { VMP }^{(1)}\end{array}$ & $\begin{array}{c}\text { CONAMA 396/08 } \\
\text { VMP(1) }\end{array}$ \\
\hline $\mathrm{pH}$ & $-x-$ & 6,0 a 9,0 & $-x-(4)$ \\
\hline Condutividade Elétrica & $\left(\mu \mathrm{S} / \mathrm{cm}\right.$ à $\left.20^{\circ} \mathrm{C}\right)$ & $-x-$ & $-x-$ \\
\hline Turbidez ${ }^{(3)}$ & uT & 5 & $-x-$ \\
\hline Sólidos totais dissolvidos & $\mathrm{mg} / \mathrm{L}$ & 1000 & $1.000 .00 \mathrm{ugL}^{-1}$ \\
\hline Cor Aparente (2) & $\mathrm{UH}$ & 15 & $-x-$ \\
\hline Dureza Total & $\mathrm{mg} / \mathrm{L}$ & 500 & $-x-$ \\
\hline Cloreto & $\mathrm{mg} / \mathrm{L}-\mu \mathrm{gl} \mathrm{L}^{-1}$ & $250 \mathrm{mg} / \mathrm{L}$ & $250.000 \mathrm{gLL}^{-1}$ \\
\hline Alcalinidade Total & $(\mathrm{mg} / \mathrm{L} \mathrm{CaCO})$ & $-x-$ & $-x-$ \\
\hline Oxigênio Dissolvido & $\mathrm{mg} / \mathrm{L}$ & $-x-$ & $-x-$ \\
\hline
\end{tabular}

NOTAS: (1) Valor máximo permitido; (2) Unidade Hazen (mgPt-Co/L); (3) Unidade de turbidez; (4) Valor não preconizado pela Portaria do Ministério da Saúde 2.914/11 e Resolução CONAMA nº 396/08.

\section{RESULTADOS E DISCUSSÃO}

A temperatura da água dos três poços, apresentou média de $32{ }^{\circ} \mathrm{C}$, variando de 30,4 a $38,7^{\circ} \mathrm{C}$ (Figura 3). A Portaria $\mathrm{n}^{\circ}$ 2.914/11 do Ministério da Saúde não determina valores de temperatura para água de consumo humano. $\mathrm{Pa}-$ ludo (2010) salienta que temperaturas mais elevadas poderão propiciar um ambiente ideal para a proliferação de microrganismos. BREUNIG et al. (2011) destacam que o aumento na temperatura eleva a taxa de reações físicas, químicas e biológicas, diminuindo as taxas de oxigênio dissolvido.

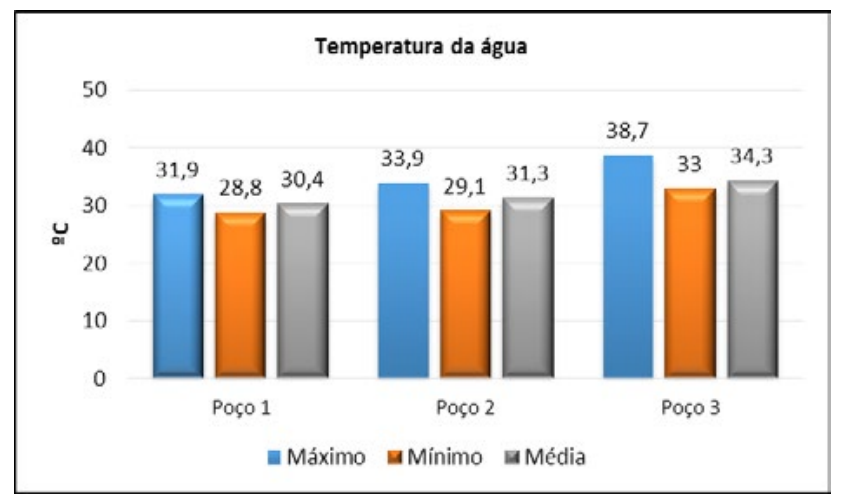

Figura 3: Variação e valor médio da temperatura da água dos três poços analisados.

Fonte: Autores (2014).

As águas subterrâneas têm uma amplitude térmica baixa, não sendo influenciada pelas variações da temperatura do ar, com exceção dos aquíferos freáticos. Em profundidade a temperatura da água pode ser influenciada pelo grau geotérmico (em média $1^{\circ} \mathrm{C}$ a cada $30 \mathrm{~m}$ ) (CORCÓVIA; CELLIGOI, 2012). Nenhum dos poços monitorados possui pro- fundidade superior a $30 \mathrm{~m}$; cujas profundidades variaram entre 10 a $15 \mathrm{~m}$.

Os valores da temperatura do ar e das águas dos três poços apresentaram valores próximos (Figura 4), exceto para o poço 3, no qual a temperatura da água apresentou valor maior que a temperatura ambiente.

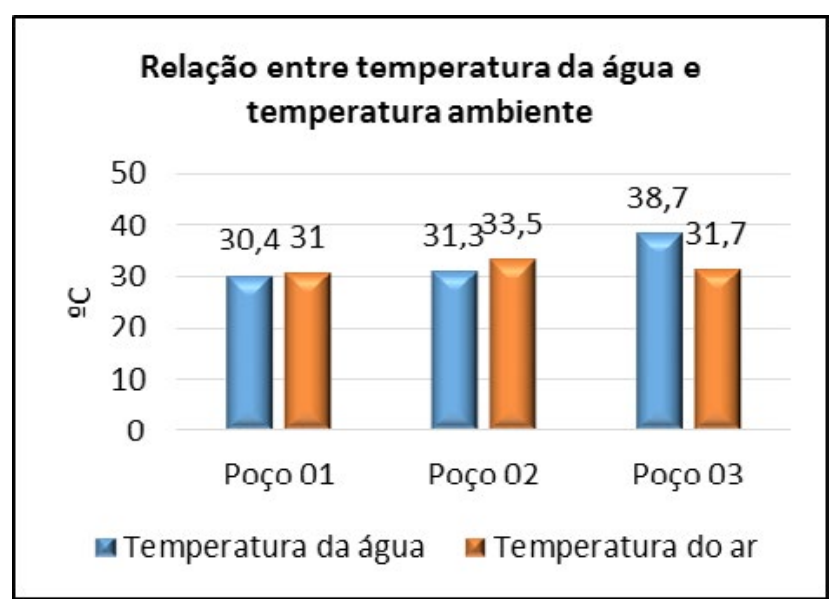

Figura 4: Valores médios da temperatura da água e a temperatura ambiente.

Fonte: Autores (2014).

$\mathrm{O}$ pH das águas subterrâneas dos três poços apresentou valores médios de P1 (8,24), P2 (8,33) e P3 (8,04) (Figura 5), enquadrando-se dentro do valor máximo permitido pela Portaria no 2.914/11 do Ministério da Saúde para águas destinadas ao consumo humano (BRASIL, 2011). De acordo Marion et al. (2007), quando o $\mathrm{pH}$ apresentar valores acima de 8,2 possivelmente seja um indicador de que alcalinidade tende para íns carbonato e/ou hidróxidos.

Segundo Peixoto (2008), quando o $\mathrm{pH}$ for maior que 7,0 contribui para o aumento da alcalinidade, ou seja, caracteriza-se como águas básicas. Além disso, águas com valores de $\mathrm{pH}$ elevado podem comprometer a palatabilidade e podem contribuir na formação de incrustações nas redes de abastecimento de água (SPERLING, 2005).

Os valores de turbidez das amostras de água dos três poços mantiveram-se dentro do valor máximo preconizado de 5,0 uT (unidade Jackson ou nefelométrica de turbidez) estabelecido pela Portaria 2.914/11 do Ministério da Saúde (Figura 6).

Segundo Obiefuna e Sheriff (2011), águas subterrâneas apresentam baixos valores de turbidez, possivelmente decorrente da ação filtrante do solo e da rocha.

Os valores de $\mathrm{CE}$ das amostras de água variaram de 1.162 a $1.217 \mu \mathrm{S} \mathrm{cm}-1$, com média de $1.202 \mu \mathrm{S} \mathrm{cm}{ }^{-1}$, (Figura 7).

Medeiros (2010) encontrou valores médios de 1.130 $\mu \mathrm{S} \mathrm{cm} \mathrm{cm}^{-1}$ e $1.645 \mu \mathrm{S} \mathrm{cm} \mathrm{cm}^{-1}$ estudos realizados nos municí- 
pios de Camalaú - PB e Amparo-PB. Enquanto Mendes et al. (2008) em pesquisa realizada no município do Congo-PB obteve valores entre $240 \mu \mathrm{S} \mathrm{cm}^{-1}$ a $4.220 \mu \mathrm{S} \mathrm{cm}-1$, com média de $1.270 \mu \mathrm{S} \mathrm{cm}-1$ no período seco.

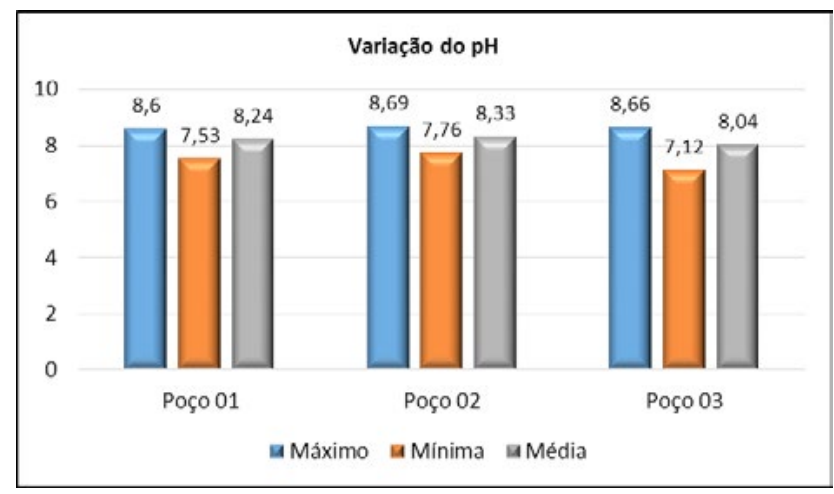

Figura 5: Valores mínimos, máximos e média de $\mathrm{pH}$ nas amostras de água dos três poços monitorados.

Fonte: Autores (2014).

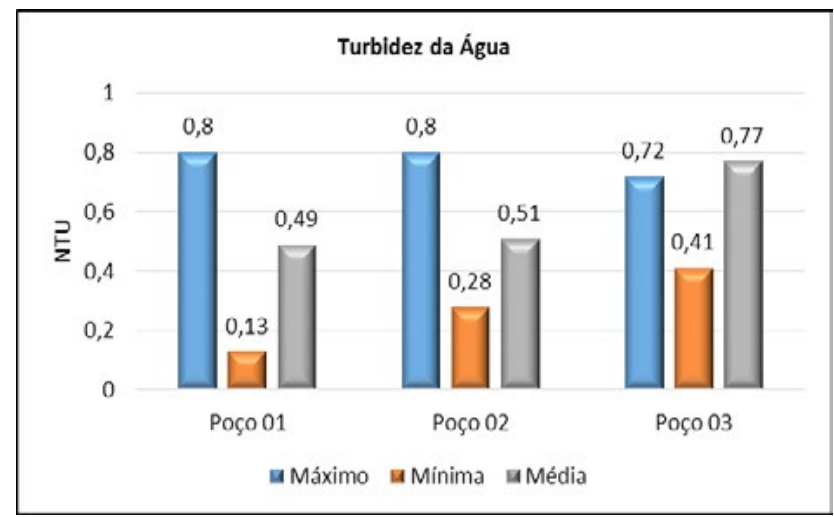

Figura 6: Valores mínimos, máximos e média de turbidez da água dos três poços.

Fonte: Autores (2014).

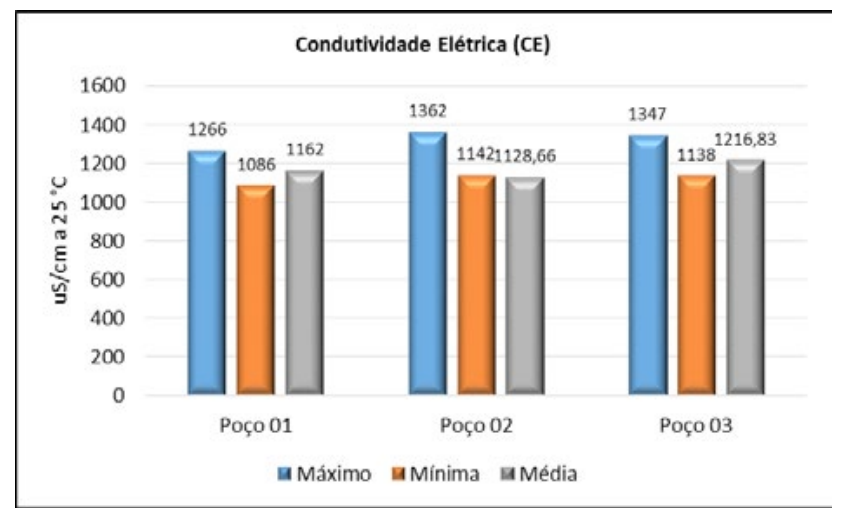

Figura 7: Valores mínimos, máximos e média de condutividade elétrica das amostras de água dos três poços analisados.

Fonte: Autores (2014).

Os valores obtidos para este parâmetro, certamente estão relacionados com a geologia e ao tipo de solo predo- minante no município de Pombal - PB, no caso o Luvissolo. Fato constatado por Santos et al. (2013) e Santos (2008) em trabalhos desenvolvidos na região semiárida. Para Mendes (2008) a evaporação elevada da água, associada à redução de precipitações pluviométricas também contribuem para uma maior concentração de sais, e consequentemente, aumenta a condutividade elétrica.

O OD nas amostras de água dos poços apresentou pequena variação e o menor valor foi de $1,0 \mathrm{mg} / \mathrm{L}$ (P2) e o maior de 1,7 mg /L, nos poços P1 e P3, respectivamente (Figura 8).

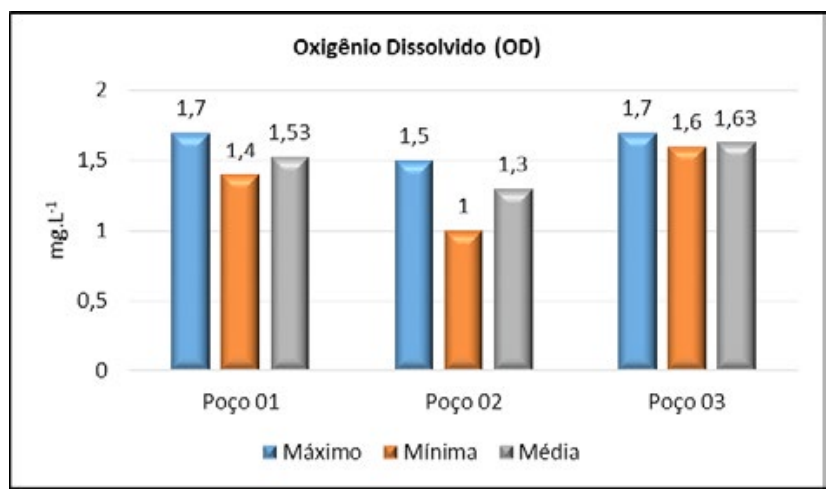

Figura 8: Valores mínimos, máximos e média de oxigênio dissolvido obtidos nas amostras de água dos três poços. Fonte: Autores (2014).

Os resultados obtidos mantiveram-se dentro do intervalo de 0 a 5 mg L-1 obtido por Feitosa; Manoel Filho (1997). Esse parâmetro não consta na Portaria no 2.914/11 do Ministério da Saúde e na Resolução CONAMA no 396/08.

Em águas subterrâneas, ocorre depleção do oxigênio, visto que não existe contato com o ar e que o O2 é consumido na decomposição de material biológico abundante.

A cor aparente nos poços 1 e 3 apresentaram resultados dentro do valor estabelecido na Portaria no 2.914/11 do Ministério da Saúde. No poço 2, em quase todas as coletas realizadas as amostras apresentaram resultados acima do limite máximo permitido de $15 \mathrm{uH}$ pela legislação (Figura 9). Neste caso, a cor aparente reflete a composição mineralógica do solo da área ou, pode ser consequência de algum composto orgânico.

A dureza total variou de $271 \mathrm{mg} \mathrm{L}^{-1}$ a $423 \mathrm{mg} \mathrm{L}-1$. Nenhuma das amostras ultrapassou o valor preconizado para potabilidade. De acordo com a Portaria 2.914/11 do Ministério da Saúde, o valor máximo permitido de dureza total para água potável é $500 \mathrm{mg} \mathrm{L}^{-1}$ de $\mathrm{CaCO}$. A classificação da dureza das águas dos três poços foi realizada de acordo com os critérios utilizados por Sawyer e McCarthy (2003) (Tabela 4).

No poço 1 a água foi classificada como dura e nos poços 2 e 3 muito dura (Figura 10). De modo geral, as águas 
subterrâneas possuem alta dureza como uma de suas particularidades (RODRIGUES NETO, 2014). Águas muito duras podem ocasionar problemas nas tubulações hidráulicas e retardo no cozimento de alimentos provocando maior consumo de gás, carvão e lenha.

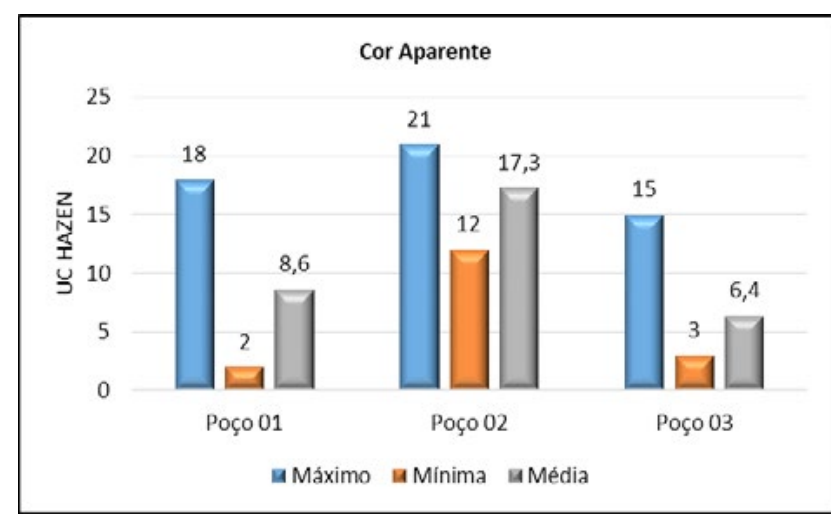

Figura 9: Valores mínimos, máximos e média de cor nas amostras de água dos três poços.

Fonte: Autores (2014).

Tabela 4: Classificação da dureza das águas subterrâneas segundo Sawyer e McCarthy (2003).

\begin{tabular}{c|c}
\hline $\begin{array}{c}\text { Dureza Total (mg/L } \\
\left.\mathbf{C a C O}_{3}\right)\end{array}$ & Classes de dureza \\
\hline$<75$ & Doce \\
\hline $75-100$ & Moderadamente dura \\
\hline $150-300$ & Dura \\
\hline$>300$ & Muito dura \\
\hline
\end{tabular}

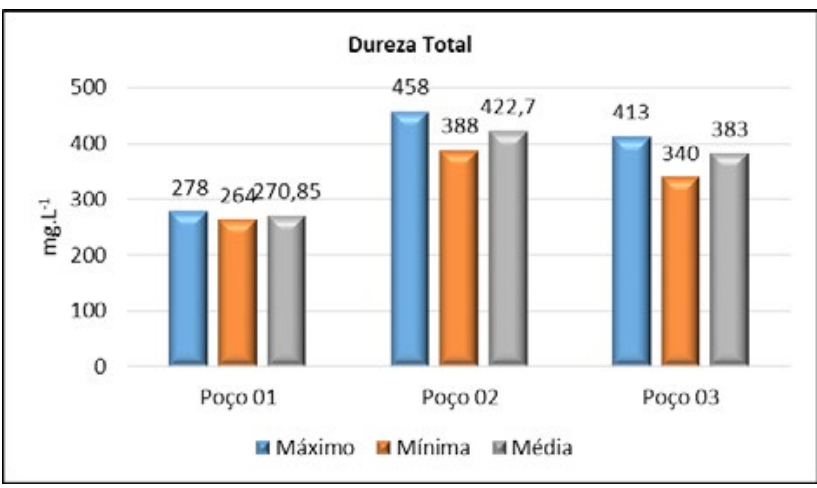

Figura 10: Valores mínimos, máximos e média de dureza total nas amostras de água dos três poços.

Fonte: Autores (2014).

As águas classificadas como muito duras são um obstáculo para o uso humano por conta do gosto desagradável, porém podem ser utilizadas para um número vasto de aplicações, como combate a incêndio, regar jardins, lavagem das ruas, e outras.

Medeiros (2010), encontrou valores de dureza total em 240 mg L-1 de CaCO3 e 488,50 mg L-1 de CaCO3 nos municípios Paraibanos de Amparo e Camalaú. Esses valores são similares aos obtidos nesta pesquisa. Possivelmente, seja em razão de que em ambos os municípios ocorre à predominância do tipo de solo Luvissolo e ambos estão inseridos na área do embasamento cristalino.

Com relação aos cloretos todas as amostras de água apresentaram resultados dentro da faixa estabelecida pela Portaria 2.914/11 do Ministério da Saúde e da Resolução CONAMA n 396/08 (Figura 11).

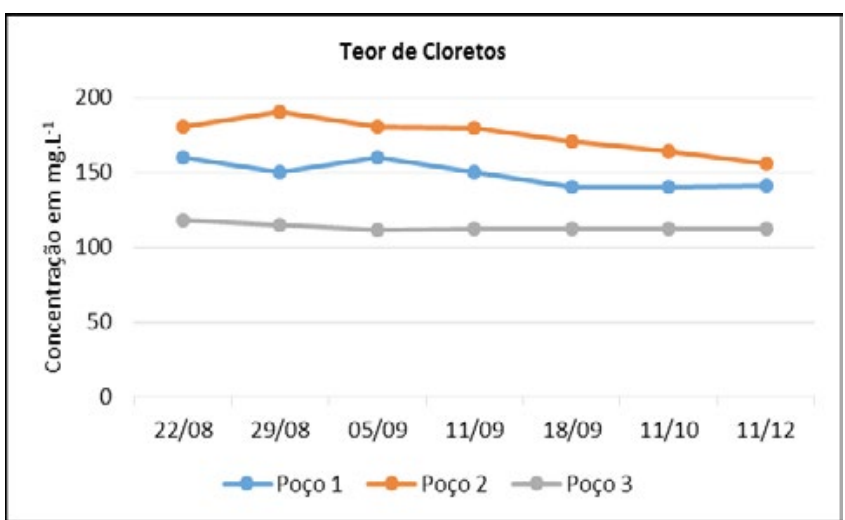

Figura 11: Concentração de cloretos nas amostras de água dos três poços nas sete campanhas. Fonte: Autores (2014).

Segundo Pohling (2009), quando são encontradas quantidades elevadas de cloretos na água e não há influências de elementos geológicos, essa contaminação possivelmente é resultante de efluentes domésticos ou industriais. Porém, na pesquisa não existe nenhuma informação a respeito dos teores de cloretos do material de origem.

Os valores de STD variaram de 568,1 a 629,14 mg/L no poço 1; de 654,76 a 698,5 mg/L no poço 2; e 665,96 a 705 $\mathrm{mg} / \mathrm{L}$ no poço 3.

Para CPRM (2005), os STD, quando em teores elevados indicam que a água tem sabor desagradável, podendo causar problemas digestivos, principalmente nas crianças, além de danificar as redes de distribuição. Este órgão, quando executou o projeto de cadastro de fontes subterrâneas no município de Pombal-PB em 2005, utilizou a classificação para STD descrita na Tabela 5.

Com base nesta classificação, verifica-se que as amostras de água dos três poços enquadram-se na categoria de água salobra. No entanto, de acordo com a Portaria 2.914/11 do Ministério da Saúde e da Resolução CONAMA de n 396/08 as amostras de água são consideradas como potáveis, visto que os resultados estão abaixo do valor máximo permitido de 1000 $\mathrm{mg} \mathrm{L}^{-1}$ (Figura 12).

A Portaria do Ministério da Saúde 2.914/11 e a Resolução CONAMA n 396/08, não preconizam um valor máximo permitido para a alcalinidade total. Por isso, levou-se em con- 
sideração o valor máximo permissível da alcalinidade total em águas para consumo da Organização Mundial de Saúde (OMS) (1999), que é $400 \mathrm{mg} \mathrm{L}^{-1}$ Com base nesta referência, verificou-se que as águas do poço 1 apresentam valores médios acima do estabelecido pela OMS e nos poços 2 e 3 , com exceção do poço 3 , na coleta 6 , mantiveram-se dentro do intervalo de potabilidade estabelecido pela OMS (Figura 13).

Tabela 5: Classificação da água para STD

\begin{tabular}{c|c}
\hline 0 a $500 \mathrm{mg} / \mathrm{L}$ & Água doce \\
\hline 501 a $1500 \mathrm{mg} / \mathrm{L}$ & Água salobra \\
\hline$>1500 \mathrm{mg} / \mathrm{L}$ & Água salgada \\
\hline
\end{tabular}

Fonte: CPRM (2005

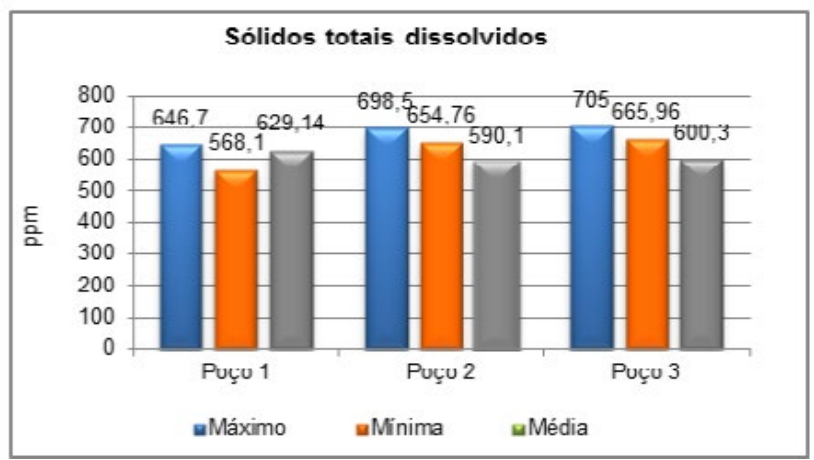

Figura 12: Valores mínimos, máximos e média dos sólidos totais dissolvidos nas amostras de água dos três poços.

Fonte: Autores (2014).

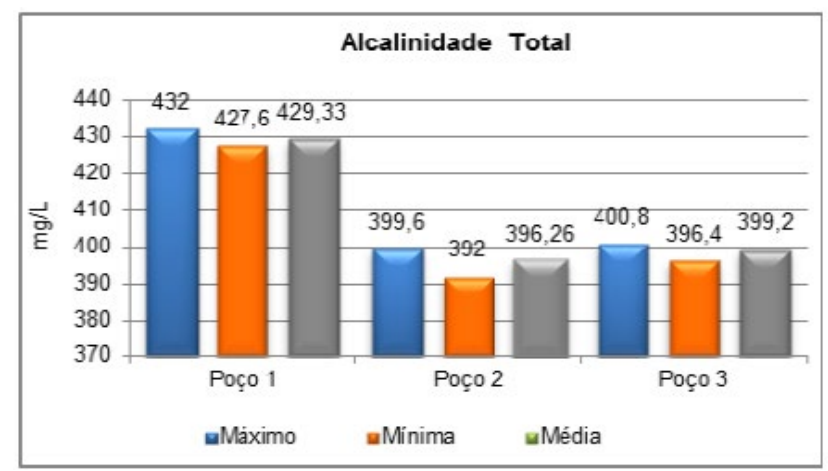

Figura 13: Valores mínimos, máximos e média de alcalinidade nas amostras de água dos três poços monitorados.

Fonte: Autores (2014)

\section{CONSIDERAÇÕES FINAIS}

Os parâmetros físicos e químicos avaliados nas amostras de águas dos três poços apresentaram valores dentro dos padrões de potabilidade preconizados pela Portaria $\mathrm{n}^{\circ}$ 2.914/11 do Ministério da Saúde e da Resolução CONAMA ñ 396/08. Embora o parâmetro alcalinidade total não tenha um limite estabelecido pelas normas brasileiras, os valores obtidos estão acima do limite máximo estabelecido pela
OMS.

Em relação à dureza da água, o poço 1 apresenta águas duras e os poços 2 e 3 muito duras.

Considerando que este é um trabalho preliminar, recomenda-se a ampliação da pesquisa para outros poços da cidade e que a avaliação e o monitoramento da qualidade da água sejam realizados contemplando o período chuvoso e seco.

\section{REFERÊNCIAS}

ALMEIDA, R. A. S. Índice de qualidade de Águas Subterrâneas Destinadas ao Uso na Produção de Água Potável (IQUAS). Salvador, 2007. 221p. Dissertação (Mestrado em Engenharia Ambiental e Urbana) - Universidade Federal da Bahia, Salvador.

AGÊNCIA NACIONAL DE ÁGUAS - ANA. Panorama da Qualidade das Águas Subterrâneas no Brasil 2005. Brasilia, 2005.

BRASIL. Conselho Nacional do Meio Ambiente. Resolução CONAMA n ${ }^{\circ} 396.03$ de abril de 2008.

BRASIL. Fundação Nacional de Saúde. Manual prático de análise de água. 2. ed. Brasilia: Fundação Nacional de Saúde, 2006. 146 p.

BRASIL. Ministério da Saúde. Portaria n ${ }^{\circ} 2.914$ de 12 de dezembro de 2011. Dispõe sobre os procedimentos de controle e de vigilância da qualidade da água para consumo humano e seu padrão de potabilidade. Diário Oficial [da República Federativa do Brasil], Brasilia, 2011, Seção 1, do dia 26 seguinte, página 266.

BREUNIG, F. M. et al. Caracterização limnológica do reservatório Rodolfo Costa e Silva - ITAARA/RS-Brasil. Revista Geográfica Acadêmica, v. 5, n. 1, p. 85-97, 2011.

BRITO, M. E. B. et al. Crescimento, fisiologia e produção do milho doce sob estresse hídrico. Biosci. J., v. 29, n. 5, p. 1244-1254, 2013.

CORCÓVIA, J. A.; CELLIGOI, A. Avaliação preliminar da qualidade da água subterrânea no município de Ibiporã-PR. Revista de estudos ambientais (REA), v. 14, n. 2, p. 39-48, 2012. 
CRISPIM, D. L. Caracterização físico-química preliminar das águassubterrâneas às margens oeste do centro da cidade de Pombal-PB. 58 p. Trabalho de Conclusão de Curso (Graduação em Engenharia Ambiental) - Universidade Federal de Campina Grande, Pombal. 2013.

CRUZ, P. et al. Estudo comparativo da qualidade físico-química da água no período chuvoso e seco na confluência dos rios Poti e Parnaíba em Teresina/PI. In: Congresso de Pesquisa e Inovação da Rede Norte Nordeste de Educação Tecnológica, 2007, João Pessoa. Anais... João Pessoa: CONNEPI, 2007.

ECKHARDT, R. R. et al. Mapeamento e avaliação da potabilidade subterrânea do município de Lajeado - RS, Brasil. Ambiente e Água - An Interdisciplinary Journal of Applied Science, v. 4, n. 1, p. 58-80, 2008.

FEITOSA, A. C. F; MANOEL FILHO, J. Hidrogeologia: conceitos e aplicações. 2. ed. Fortaleza: CPRM/ REFO, LABHID - UFPE, 2000. 391p.

GUIMARÃES, C. S. Saneamento Básico. 2007, Rio de Janeiro - RJ, 68 p. Disponível em: http://www.ufrrj.br/ institutos/it/deng/leon ardo/downloads/APOSTILA/ Apostila\%20IT\%20179/Capit\%204\%20parte\%202.pdf.> Acesso em: 16 Ago. 2016.

INSTITUTO BRASILEIRO DE GEOGRAFIA E ESTATÍSTICA - IBGE. Censo Demográfico 2010. Rio de Janeiro: IBGE, 2000. Disponível em:< http:/ / http:/ / www. cidades.ibge.gov.br/xtras/perfil.php?lang $=$ \&codmun $=251$ 210\&search=paraiba $\mid$ pombal>. Acesso em: 17 fev. 2015.

LINHARES, F. M. Vulnerabilidade intrínseca e risco de contaminação do aquífero livre da bacia hidrográfica do rio Gramame-PB. 91p. Dissertação (Mestrado em Engenharia Urbana e Ambiental) - Universidade Federal da Paraíba, João Pessoa. 2012.

MARION, F. A.; CAPOANE, V.; SILVA, J. L. S. da. Avaliação da qualidade da água subterrânea em poço no campus da UFSM, Santa Maria - RS. Revista Ciência e Natura, v. 29, n. 1, p. 97 - 109, 2007.

MEDEIROS, J. X. de. Qualidade das fontes hídricas na região do alto curso do rio Paraíba e análises multivariadas na hierarquização dos componentes principais. 111p. Tese (Doutorado em Engenharia Agrícola) - Uni- versidade Federal de Campina Grande, Campina Grande. 2010.

MENDES, J. da S.; CHAVES, L. H. G.; CHAVES, I. de B. Qualidade de água para consumo humano em comunidades rurais do município de Congo, PB. Revista Ciência Agronômica, v. 39, n. 02, p. 333-342, 2008.

MOLOZZI, J.; PINHEIRO, A.; SILVA, M. R. da Qualidade da água em diferentes estádios de desenvolvimento do arroz irrigado. Pesquisa Agropecuária Brasileira, v.41, n.9, p. 1393- 1398, 2006.

MONTENEGRO, A. A. A.; MONTENEGRO, S. M. G. L. Olhares sobre as políticaspúblicas de recursos hídricos para o semiárido. In: GHEYI, H. R.; PAZ, V. P. da S.;MEDEIROS, S. de S.; GALVÃO, C de O. Recursos hídricos em regiõessemiáridas: estudos e aplicações. Campina Grande: Instituto Nacional do Semiárido, 2012. p. 8.

OBIEFUNA, G. I.; SHERIFF, A. Assessment of Shallow Ground Water Quality of Pindiga Gombe Area, Yola Area, NE, Nigeria for Irrigation and Domestic Purposes. Research Journal of Environmental and Earth Sciences, v.3, p.131-141, 2011.

ORGANIZATION MUNDIAL DE LA SALUD. Guias para la calidad del água potable. 2. ed. v. 1., Genebra: OMS, 1999.

PALUDO, D. Qualidade da água nos poços artesianos do município de Santa Clara do Sul. 69p. Trabalho de Conclusão de Curso (Graduação em Química Industrial) Centro Universitário UNIVATES, Lajeado.2014.

PEIXOTO. J. Documento adaptado das aulas de Elementos de Engenharia do Ambiente. MIEB - 2008.

POHLING, R. Reações químicas na análise de água. Fortaleza: Arte Visual, 2009.

RODRIGUES NETO, M. P. Estudo da Qualidade de Águas de Poços no Iguape-CE. 63p. Dissertação (Mestrado em Engenharia Civil e Saneamento Ambiental) - Universidade Federal do Ceará, Fortaleza. 2014.

SANTOS, H. G. et al. Sistema brasileiro de classificação de Solos, 3. ed. Brasília: EMBRAPA Solos, 2013. 353 p. 
SANTOS, R. T. dos. Identificação e caracterização de corpos de água salinas no semiárido Paraibano. 67p Dissertação (Mestrado em Engenharia Agrícola) - Universidade Federal de Campina Grande, Campina Grande. 2008.

SAWYER, N. N.; McCARTY, P. L.; PARKIN, G. F. Chemistry for environmental engineering and Science. 5. ed. New York: McGraw-Hill, 2003. 752 p.

SERVIÇO GEOLÓGICO DO BRASIL - CPRM. Projeto Cadastro de Fontes de Abastecimento por Água Subterrânea: Diagnóstico do Município de Pombal, estado da Paraíba. Recife: CPRM/PRODEEM, 2005.

SPERLING, M. V. Introdução à qualidade das águas $\mathbf{e}$ ao tratamento de esgotos. 3. ed. Belo Horizonte: DESA/ UFMG, 2005.

Correspondência dos autores:

Diêgo Lima Crispim

e-mail: dlimacrispim@gmail.com

Andréa Maria Brandão Mendes de Oliveira

e-mail: andrea.maria@ufcg.edu.br

Alan Dél Carlos Gomes Chaves

e-mail: alandcgc@hotmail.com

Luiz Fernando de Oliveira Coelho

e-mail:1uisfoc@ccta.ufcg.edu.br

Sanduel Oliveira de Andrade

e-mail: sanduelandrade@hotmail.com

Artigo recebido em: 31/05/2016

Revisado pelo autor em: 02/03/2017

Aceito para publicação em: 07/05/2017

Geografia, Ensino \& Pesquisa, Vol. 21 (2017), n.2, p. 155-163 